\title{
The thermogenic effect of nesfatin-1 requires recruitment of the melanocortin system
}

\author{
Riccardo Dore1, Luka Levata', Sogol Gachkar1, Olaf Jöhren², Jens Mittag', \\ Hendrik Lehnert ${ }^{1}$ and Carla Schulz ${ }^{1}$
}

'Department of Internal Medicine I, Center of Brain, Behavior and Metabolism (CBBM), University of Lübeck, Lübeck, Germany

${ }^{2}$ Center of Brain, Behavior and Metabolism (CBBM), University of Lübeck, Lübeck, Germany
Correspondence should be addressed to C Schulz

Email

carla.schulz@uksh.de

\begin{abstract}
Nesfatin-1 is a bioactive polypeptide expressed both in the brain and peripheral tissues and involved in the control of energy balance by reducing food intake. Central administration of nesfatin-1 significantly increases energy expenditure, as demonstrated by a higher dry heat loss; yet, the mechanisms underlying the thermogenic effect of central nesfatin-1 remain unknown. Therefore, in this study, we sought to investigate whether the increase in energy expenditure induced by nesfatin- 1 is mediated by the central melanocortin pathway, which was previously reported to mediate central nesfatin-1's effects on feeding and numerous other physiological functions. With the application of direct calorimetry, we found that intracerebroventricular nesfatin-1 $(25 \mathrm{pmol})$ treatment increased dry heat loss and that this effect was fully blocked by simultaneous administration of an equimolar dose of the melanocortin $3 / 4$ receptor antagonist, SHU9119. Interestingly, the nesfatin-1-induced increase in dry heat loss was positively correlated with body weight loss. In addition, as assessed with thermal imaging, intracerebroventricular nesfatin-1 $(100 \mathrm{pmol})$ increased interscapular brown adipose tissue (iBAT) as well as tail temperature, suggesting increased heat production in the iBAT and heat dissipation over the tail surface. Finally, nesfatin-1 upregulated pro-opiomelanocortin and melanocortin 3 receptor mRNA expression in the hypothalamus, accompanied by a significant increase in iodothyronine deiodinase 2 and by a nonsignificant increase in uncoupling protein 1 and peroxisome proliferatoractivated receptor gamma coactivator-1 alpha mRNA in the iBAT. Overall, we clearly demonstrate that nesfatin-1 requires the activation of the central melanocortin system to increase iBAT thermogenesis and, in turn, overall energy expenditure.
\end{abstract}

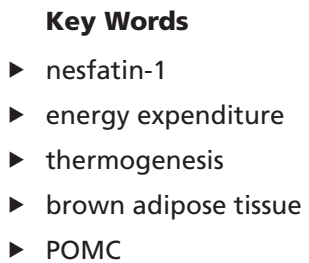

Journal of Endocrinology (2017) 235, 111-122

\section{Introduction}

Nesfatin-1 is a cleavage product of nucleobindin 2 (NUCB2), the sequence of which is highly conserved from fish to mammals. Nesfatin-1 was reported for the first time by Oh-I et al. (2006) to possess anorexigenic properties. The effect of nesfatin-1 on feeding behavior was subsequently independently confirmed by other research groups (Maejima et al. 2009, Stengel et al. 2009a, Yosten \& Samson 2010, Wernecke et al. 2014). In addition to the 
ability of nesfatin- 1 to suppress food intake, it was shown that intracerebroventricular (i.c.v.) administration of nesfatin-1 increases core body temperature (Könczöl et al. 2012) and dry heat loss (Wernecke et al. 2014), thus indicating its major role in the regulation of energy homeostasis. However, the underlying mechanisms are poorly understood.

In the brain, and in agreement with its role in the control of energy balance, NUCB2/nesfatin-1 is highly expressed in several hypothalamic nuclei such as paraventricular (PVN), supraoptic (SON) and arcuate (Arc) nucleus, as well as in the brainstem (Oh-I et al. 2006, Brailoiu et al. 2007, Foo et al. 2008, Goebel et al. 2009, Goebel-Stengel et al. 2011). In agreement, site-specific administration of nesfatin-1 into the PVN induces anorexia and sympathetic nerve activity (Tanida et al. 2015). Notably, endogenous NUCB2/nesfatin-1 levels depend upon the metabolic state. For instance, Nucb2 mRNA and NUCB2/nesfatin-1 protein levels were found to be reduced by fasting, and restored by re-feeding, both centrally in the SON and PVN (Oh-I et al. 2006, Kohno et al. 2008, García-Galiano et al. 2010), as well as peripherally in subcutaneous adipose tissue (Ramanjaneya et al. 2010) and plasma (Stengel et al. 2009b).

The central NUCB2/nesfatin-1 system was reported to interact with the melanocortin system (Oh-I et al. 2006, Yosten \& Samson 2009, 2014), oxytocin (Maejima et al. 2009, Yosten \& Samson 2010, 2014, Nakata et al. 2016), corticotropin-releasing factor (CRF) (Stengel et al. 2009a, Yosten \& Samson 2014, Feng et al. 2017), neuropeptide Y (NPY) (Price et al. 2008, Inhoff et al. 2010, Sedbazar et al. 2014) and others (Dore et al. 2016). Among these, the central melanocortin system appears to be of particular importance. The nesfatin-1-induced suppression of food intake, increase in mean arterial pressure and sympathetic nerve activity are prevented by the co-administration of the melanocortin 3/4 receptor (MC3/4R) antagonist SHU9119, indicating the recruitment of the central melanocortin system by nesfatin-1. Similarly, stimulation of central MC4R suppresses food intake and increases energy expenditure (Fan et al. 1997, Hwa et al. 2001) by enhancing sympathetic nerve activity, uncoupling protein 1 (Ucp1) mRNA expression and temperature in interscapular brown adipose tissue (iBAT) (Williams et al. 2003, Fan et al. 2007, Song et al. 2008). The hypothalamus was shown to be pivotal in mediating these effects (Song et al. 2008, Monge-Roffarello et al. 2014b, Zhang \& Bi 2015). In support of this, studies employing retrograde tracers revealed the existence of a direct connection between hypothalamic nuclei and iBAT (Bamshad et al. 1999,
Oldfield et al. 2002). Of note, the majority of proopiomelanocortin (POMC) neurons originate in the Arc, where POMC and NUCB2/nesfatin-1 are co-localized (Foo et al. 2008). Furthermore, alpha-melanocytestimulating hormone (aMSH) treatment increases Nucb2 mRNA expression (Oh-I et al. 2006) and calcium influx in NUCB2/nesfatin-1 neurons of the PVN (Sedbazar et al. 2014). These findings point toward the hypothalamus, as an important relay center for the interaction of NUCB2/nesfatin-1 and the melanocortin system.

In the present study, we sought to further characterize the effects of nesfatin-1 on energy expenditure. We hypothesized that nesfatin-1's thermogenic effects are mediated by the recruitment of the central melanocortin system. For this purpose, we employed a recently developed direct calorimetry system (Wernecke et al. 2014) to measure dry heat loss upon i.c.v. nesfatin-1 administration with or without concurrent administration of SHU9119. Additionally, we used infrared thermal imaging to measure skin temperature of the iBAT region, ear and tail, for the identification of heat sources and dissipation. Finally, the expression of melanocortin system genes, as well as thermogenesis-related markers, was measured by quantitative real-time PCR in hypothalamus and iBAT, respectively, following i.c.v. nesfatin-1 administration.

\section{Materials and methods}

\section{Animals}

For in vivo studies, male Wistar rats, weighing 251-275g at arrival (Charles River, Sulzfeld, Germany), were housed in wire-topped, plastic cages, in a 12-h/12-h light/dark cycle (lights off at $6: 00 \mathrm{~h})$ temperature-controlled $\left(21^{\circ} \mathrm{C}\right)$ vivarium. Rats had ad libitum access to regular rodents chow (Altromin 1324, Altromin, Lage, Germany) and water, unless otherwise stated. The experimental protocols for animals and their care were in accordance with the German law and were approved by the committee on animal care of the state of Schleswig-Holstein, Germany. In all experiments, the 'Principles of Laboratory Animal Care' (NIH publication no. 85-23, revised 1985; http:// grants1.nih.gov/grants/olaw/references/phspol.htm) were followed.

\section{Stereotaxic surgery and microinjection procedures}

The surgical procedure was performed as previously described (Dore et al. 2013). Anesthetized (ketamine $80 \mathrm{mg} / \mathrm{kg}$; xylazine $6 \mathrm{mg} / \mathrm{kg}$ ) rats underwent unilateral

Published by Bioscientifica Ltd 
implantation of a 24-gauge stainless steel cannula (PlasticsOne, Roanoke, VA, USA) under stereotaxic control (Kopf Instruments, Tujunga, CA, USA) into the lateral ventricle using the following coordinates (from bregma, in $\mathrm{mm}$ ): AP: -1.0 , ML: \pm 1.5 , DV: -2.3 from skull, with the incisor bar set at $-3.3 \mathrm{~mm}$ below the interaural line, according to Paxinos \& Watson (2007). On the experimental day, the dummy cannula was removed to insert an injector (1.5 $\mathrm{mm}$ protrusion) into the guide cannula. i.c.v. injection of substances $(5 \mu \mathrm{L})$ was performed manually in freely moving animals by a $10 \mu \mathrm{L}$ Hamilton syringe (CS-Chromatographie Service GmbH, Langerwehe, Germany) over $2 \mathrm{~min}$. One week after surgery, cannula placement was confirmed by a positive dipsogenic response to i.c.v. angiotensin II $(24 \mathrm{pmol} / 5 \mu \mathrm{L}$; Sigma-Aldrich). All the animals showed an intake $\geq 10 \mathrm{~mL}$ of water within $15 \mathrm{~min}$.

\section{Pharmacological treatments}

Rat nesfatin-1, purchased from Phoenix Europe GmbH (Karlsruhe, Germany), was used in both in vivo and in vitro studies. For in vivo studies, doses were selected based on previous reports (Könczöl et al. 2012, Wernecke et al. 2014, Yilmaz et al. 2015). SHU9119 was purchased from Tocris (Bristol, UK). Both drugs were dissolved in sterile phosphate-buffered saline (PBS) that served as control solution. Nesfatin-1 and SHU9119 were administered $(5 \mu \mathrm{L})$ as a cocktail in a single injection. The assessment by $12 \%$ polyacrylamide gel electrophoresis (PAGE) showed that nesfatin-1 remains intact when applied together with SHU9119 (Supplementary Fig. 1A, see section on supplementary data given at the end of this article). Drug aliquots were kept at $-80^{\circ} \mathrm{C}$ and freshly prepared on the experimental day.

\section{Direct calorimetry}

Direct calorimetry was performed using the setup described previously (Wernecke et al. 2014). Fasted (24-h) rats were assigned to the experimental groups after matching their body weight (BW) prior to starvation (nesfatin-1 $\times$ SHU9119: $\quad F(1,33)=0.00, \quad$ n.s.), after starvation (nesfatin- $1 \times$ SHU9119: $F(1,33)=0.06$, n.s.) and BW loss (nesfatin- $1 \times$ SHU9119: $F(1,33)=0.15$, n.s.). Immediately after i.c.v. drugs administration (h 09:00), rats were placed into the calorimeters for an 8-h period during which food was not supplied. Experimental room temperature during the experiment was $21 \pm 1^{\circ} \mathrm{C}$. At the end of the experiment, rats were weighed, returned to the vivarium and left undisturbed for a washout period of 5-7 days, during which they had ad libitum access to food and water.

\section{Infrared thermal imaging}

Thermal imaging was performed using a FLIR A-65 infrared thermography camera (infrared resolution $640 \times 512$ pixels, thermal sensitivity $<0.05^{\circ} \mathrm{C}$ at $+30^{\circ} \mathrm{C}$ ). Images of the interscapular region, proximal tail and auditory canal of the ear (ear) were assessed as indices of iBAT heat production, heat dissipation and core body temperature, respectively. Additionally, images of the ocular surface (eye) were taken as supplementary index of core body temperature (Vogel et al. 2016) and compared with data from the ear (Supplementary Fig. 4). Both ear and eye temperature are significantly correlated with the rectal temperature (ear/rectal: $r=0.455, P<0.001$; eye/ rectal: $r=0.508, P<0.0001$; Supplementary Fig. $1 \mathrm{~B}$ and C).

Fasted (24-h) rats were assigned to the experimental groups after matching their BWs prior to starvation $(t(13)=-0.34$, n.s. $)$, after starvation $(t(13)=0.20$, n.s. $)$, BW loss $(t(13)=0.88$, n.s.) and iBAT temperature in basal condition $(t(13)=-0.53$, n.s.). The interscapular region of the rats was shaved two days before the experiment. The rats were handled extensively and habituated to the experimental procedures for four consecutive days, so that the variation of iBAT temperature was $\pm 1.2 \%$ over four pictures taken 30-min apart. Two hours prior to the experiment, rats were moved to the experimental room (temperature $21 \pm 1^{\circ} \mathrm{C}$ ) and left undisturbed with ad libitum access to water, but not to food. Rats were gently and quickly removed from their home cages, placed under the camera, and images of iBAT region, ear and tail were taken over a $\sim 30$-s period. Immediately after baseline measurements, i.c.v. injections were performed as mentioned before. The animals were then returned to their home cages and left undisturbed until the subsequent measurements. At the end of the experiment, rats were weighed, returned to the vivarium and left undisturbed for a washout period of 5-7 days during which they had ad libitum access to food and water. By using FLIR QuickReport 1.2 software, a set of three images per region of interest (interscapular region, ear, eye, proximal tail) was scored for each animal at each time-point to calculate the respective mean temperature. The maximal mean temperature of each set was then considered for final analysis. (c) 2017 Society for Endocrinology Printed in Great Britain
Published by Bioscientifica Ltd 


\section{Tissue collection}

Fasted (24-h) rats were assigned to the experimental groups after matching their BWs prior to starvation $(t(9)=-0.76$, n.s. $)$, after starvation $(t(9)=-0.59$, n.s. $)$ and BW loss $(t(9)=-0.72$, n.s.). The animals received an i.c.v. injection of either PBS or nesfatin-1 (100 pmol/rat), and iBAT temperature was monitored for $4 \mathrm{~h}$, after which the rats were killed by decapitation, and brains were quickly removed, immediately deep frozen in dry ice and stored at $-80^{\circ} \mathrm{C}$. The skin overlaying the interscapular region was incised and a sample of the iBAT was carefully dissected from adjacent tissues. Inguinal WAT (iWAT) was dissected through an incision in the skin along the bottom of the rib cage. Both iBAT and iWAT were further processed as described for the brain. The time-point of the sacrifice was chosen based on the findings from direct calorimetry and thermal imaging assessment.

\section{Dissection of hypothalamus, RNA isolation, CDNA synthesis and $\mathrm{qPCR}$}

Dissection of hypothalamus, extraction of total RNA from hypothalamus, iBAT and iWAT, and synthesis of the first-strand cDNA were performed as previously described (Jöhren et al. 2003). Tissue mRNA levels were determined by qRT-PCR as reported earlier (Schulz et al. 2012). Oligonucleotide primers were obtained from Invitrogen (Supplementary Table 1).

\section{Western blot analysis}

Fasted (24-h) rats of a different cohort were assigned to the experimental groups after matching their BWs prior to starvation $(t(10)=-0.12$, n.s.), after starvation $(t(10)=-0.18$, n.s. $)$, BW loss $(t(10)=0.12$, n.s. $)$ and iBAT temperature in basal condition $(t(10)=-0.07$, n.s.). The animals were killed $4 \mathrm{~h}$ following an i.c.v. injection of either PBS or nesfatin-1 (100 pmol/rat). A sample of the iBAT was dissected as described previously. Western blot analysis was performed as previously described (Hoefig et al. 2016). Individual UCP1 (rabbit antibody raised against hamster, see (Jastroch et al. 2012)) protein level values were normalized to those of heat-shock protein 90 (HSP90; antibody \#4877S, Cell Signaling Technology) and expressed as percent of PBS group.

\section{Contractile response studies using myography}

A wire myograph (520A-DMT, AD Instruments, Dunedin, New Zealand) was used to measure the contractility of vessels as described previously (Warner et al. 2013). Short pieces of aorta or tail artery were dissected from male C57BL/6N wild-type mice and mounted into the wire myograph using stainless steel wires $(40 \mu \mathrm{m}$ diameter, DMT). The chamber of the wire myograph was filled with Krebs-Ringer buffer $(123 \mathrm{mM} \mathrm{NaCl}, 4.7 \mathrm{mM} \mathrm{KCl}, 1.2 \mathrm{mM}$

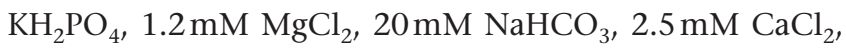
$5.5 \mathrm{mM}$ glucose) and gassed with carbogen gas to yield $\mathrm{pH}$ 7.4 at $37^{\circ} \mathrm{C}$. Vessels were allowed to recover for $1 \mathrm{~h}$. With the application of increasing tension forces and recording the corresponding contraction, the optimal tension was determined. Vessels were pre-stimulated with either $10 \mathrm{nM}$ nesfatin-1 or PBS for $3 \mathrm{~min}$. To perform a dose-response curve, increasing doses of phenylephrine (Sigma-Aldrich) $\left(10^{-8}\right.$ to $\left.10^{-2} \mathrm{M}\right)$ were added in 2 -min intervals into the chamber. The induced force was detected and normalized by the previously recorded $\mathrm{KCl}$ stimulation force using Labchart software 8.1.

\section{Statistical analysis}

The effect of drugs on dry heat loss over 8-h period was analyzed using three-way repeated measure analysis of variance (ANOVAs) with nesfatin-1 and SHU9119 as between-subjects factors and time as within-subject factor. Single time-point measurements were analyzed using a two-way ANOVA with nesfatin-1 and SHU9119 as between-subjects factors. Pairwise post hoc comparisons were made using Newman-Keuls. The effect of nesfatin-1 on iBAT, ear and tail temperature was analyzed using two-way ANOVA with nesfatin-1 as between-subjects factor and time as within-subject factor. Single time-point measurements were analyzed using Student's $t$-test. Levels of mRNA and protein expression were also analyzed using Student's $t$-test. Correlation between two variables was performed using Spearman's rank correlation coefficient. Dose-response curves were generated using least-square fit and tested for differences between the two data sets using Student's $t$-test. Significance was set at $P<0.05$. All data are expressed as mean \pm standard deviation (s.D.). The software packages used were Excel, SigmaPlot 11.0, GraphPad 6.0 and Statistica 7.0.

\section{Results}

\section{The MC3/4 receptor antagonist SHU9119 blocks nesfatin-1-induced increase in thermogenesis}

As shown in Fig. 1, i.c.v. administration of nesfatin-1 (25 pmol/rat) significantly affected dry heat loss, as reflected

Published by Bioscientifica Ltd. 


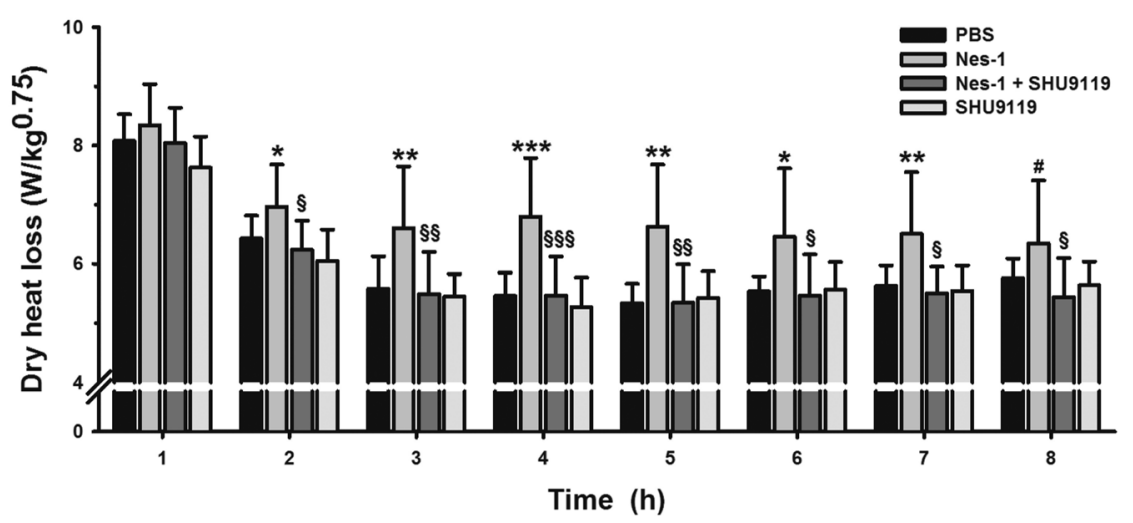

\begin{abstract}
Figure 1
Effect of i.c.v. administration of nesfatin-1 ( $25 \mathrm{pmol} / \mathrm{rat}$ ) and MC3/4R antagonist ( $25 \mathrm{pmol} / \mathrm{rat}$ ) on dry heat loss measured through direct calorimetry. 24-h fasted rats (9-10/group) were placed in the calorimeters immediately after drug administration $(5 \mu \mathrm{L} / 2 \mathrm{~min})$ and tested for 8-h during the light phase. Data represent mean \pm s.D. ${ }^{\#} P \leq 0.1$ vs PBS group; $* P<0.05, * * P<0.01, * * * P<0.001$ vs $\mathrm{PBS}$ group; ${ } P<0.05,{ }^{\S} P<0.01,{ } \S \S P<0.001$ vs nesfatin-1 group (Newman-Keuls test).
\end{abstract}

by a significant effect of nesfatin- $1(F(1,33)=6.30, P<0.05)$. Post hoc comparisons revealed that nesfatin-1 increased dry heat loss after $3 \mathrm{~h}(P<0.01 ;+18 \%), 4 \mathrm{~h}(P<0.001 ;+24 \%)$, $5 \mathrm{~h}(P<0.01 ;+24 \%)$, $6 \mathrm{~h}(P<0.05 ;+17 \%)$ and $7 \mathrm{~h}(P<0.01$; $+16 \%)$ compared with PBS-treated group. An equimolar dose of the MC3/4R antagonist SHU9119 (25 pmol/rat), which had no effect on dry heat loss per se, was able to fully block the thermogenic effect induced by nesfatin-1, as demonstrated by a significant interaction nesfatin- $1 \times$ SHU9119 $(F(1,33)=6.30, P<0.05)$. Post hoc comparisons revealed that SHU9119, administered in combination with nesfatin-1, decreased dry heat loss after 3 h $(P<0.01 ;-17 \%)$, 4 h $(P<0.001 ;-20 \%)$, 5 h $(P<0.01$; $-19 \%)$, $6 \mathrm{~h} \quad(P<0.05 ;-15 \%)$ and $7 \mathrm{~h} \quad(P<0.05 ;-15 \%)$ compared with nesfatin-1-treated group.

On average (hour 2-8), i.c.v. administration of nesfatin-1 significantly increased dry heat loss $(P<0.01$; $+16 \%$ vs PBS), an effect that was abolished by the co-administration of an equimolar dose of SHU9119 $(P<0.01 ;-16 \%$ vs nesfatin-1) (Supplementary Fig. 2).

\section{Nesfatin-1-induced increase in dry heat loss correlates with body weight loss}

Although central nesfatin-1 administration did not significantly affect BW loss over the 8-h period of direct calorimetry session (nesfatin-1: $F(1,33)=1.91$, n.s.; SHU9119 $\times$ nesfatin-1: $F(1,33)=1.33$, n.s.; Fig. $2 \mathrm{~A})$, the analysis revealed significant correlation between dry heat loss and BW loss in the nesfatin-1-treated group ( $r=0.879, P<0.001)$ but not in the other treatment groups (PBS: $r=0.142$, n.s.; SHU9119+ nesfatin-1: $r=0.500$, n.s.; SHU9119: $r=-0.059$, n.s.) (Fig. 2B).

\section{Nesfatin-1 increases iBAT, ear and tail temperature}

I.c.v. administration of a higher dose of nesfatin-1 (100 pmol/rat) caused a significant increase in iBAT temperature, as demonstrated by significant effects of nesfatin-1 $(F(1,13)=15.70, P<0.01)$, time $(F(7,91)=9.00$, $P<0.001)$ and nesfatin- $1 \times$ time $(F(7,91)=3.80, P<0.01$; Fig. 3A and B). Nesfatin-1-treated group displayed a higher iBAT temperature at $2 \mathrm{~h}(t(13)=-2.48, P<0.05 ;+1.4 \%)$, $3 \mathrm{~h} \quad(t(13)=-3.73, \quad P<0.01 ;+2.0 \%), 4 \mathrm{~h} \quad(t(13)=-3.30$, $P<0.01 ;+2.2 \%), 5 \mathrm{~h}(t(13)=-3.37, P<0.01 ;+2.9 \%), 6 \mathrm{~h}$ $(t(13)=-4.84, P<0.001 ;+2.7 \%)$ and $7 \mathrm{~h}(t(13)=-3.20$, $P<0.01 ;+2.6 \%)$ than PBS-treated group. On average (hour 1-8), i.c.v. administration of nesfatin-1 significantly increased iBAT temperature $(t(13)=-3.96, P<0.01 ;+1.6 \%$ vs PBS; Fig. 3A inset).

Nesfatin-1 also induced an increase in ear temperature, as revealed by significant effects of nesfatin-1 $(F(1,13)=4.90, P<0.05)$, time $(F(7,91)=11.30$, $P<0.001) \quad$ and nesfatin-1 $\times$ time $\quad(F(7,91)=2.10$, $P<0.05$; Fig. 3C and D). The nesfatin-1-treated group exhibited a higher ear temperature at $3 \mathrm{~h}(t(13)=-2.07$, $P=0.06 ;+1.1 \%), 4 \mathrm{~h} \quad(t(13)=-2.09, P=0.06 ;+1.4 \%)$, $5 \mathrm{~h} \quad(t(13)=-2.33, P<0.05 ;+2.5 \%), 6 \mathrm{~h} \quad(t(13)=-2.50$, $P<0.05 ;+1.7 \%)$ and $7 \mathrm{~h}(t(13)=-2.02, P=0.06 ;+1.7 \%)$ than PBS-treated group. On average (hour 1-8), i.c.v. administration of nesfatin-1 significantly increased ear temperature $(t(13)=-2.21, P<0.05 ;+1.0 \%$ vs PBS; Fig. 3C inset).

I.c.v. administration of nesfatin-1 also resulted in an increase in tail temperature, as revealed by a significant effect of nesfatin-1 $(F(1,13)=4.92$, $P<0.05)$ and time $(F(7,91)=8.43, P<0.001)$, whereas interaction between nesfatin- $1 \times$ time was approaching significance $(F(7,91)=2.06, \quad P=0.06$; Fig. $3 \mathrm{E}$ and $\mathrm{F})$. Nesfatin-1-treated group showed a higher tail temperature at $1 \mathrm{~h}(t(13)=-2.37, P<0.05 ;+4.2 \%), 4 \mathrm{~h}(t(13)=-2.06$, $P=0.06 ;+2.1 \%), 5 \mathrm{~h}(t(13)=-2.00, P=0.07 ;+3.1 \%)$ and $8 \mathrm{~h}(t(13)=-2.58, P<0.05 ;+3.9 \%)$ than PBS-treated group. On average (hour 1-8), i.c.v. administration of nesfatin-1 significantly increased tail temperature $(t(13)=-2.22$, $P<0.05 ;+1.6 \%$ vs PBS; Fig. 3E inset).

Published by Bioscientifica Ltd 

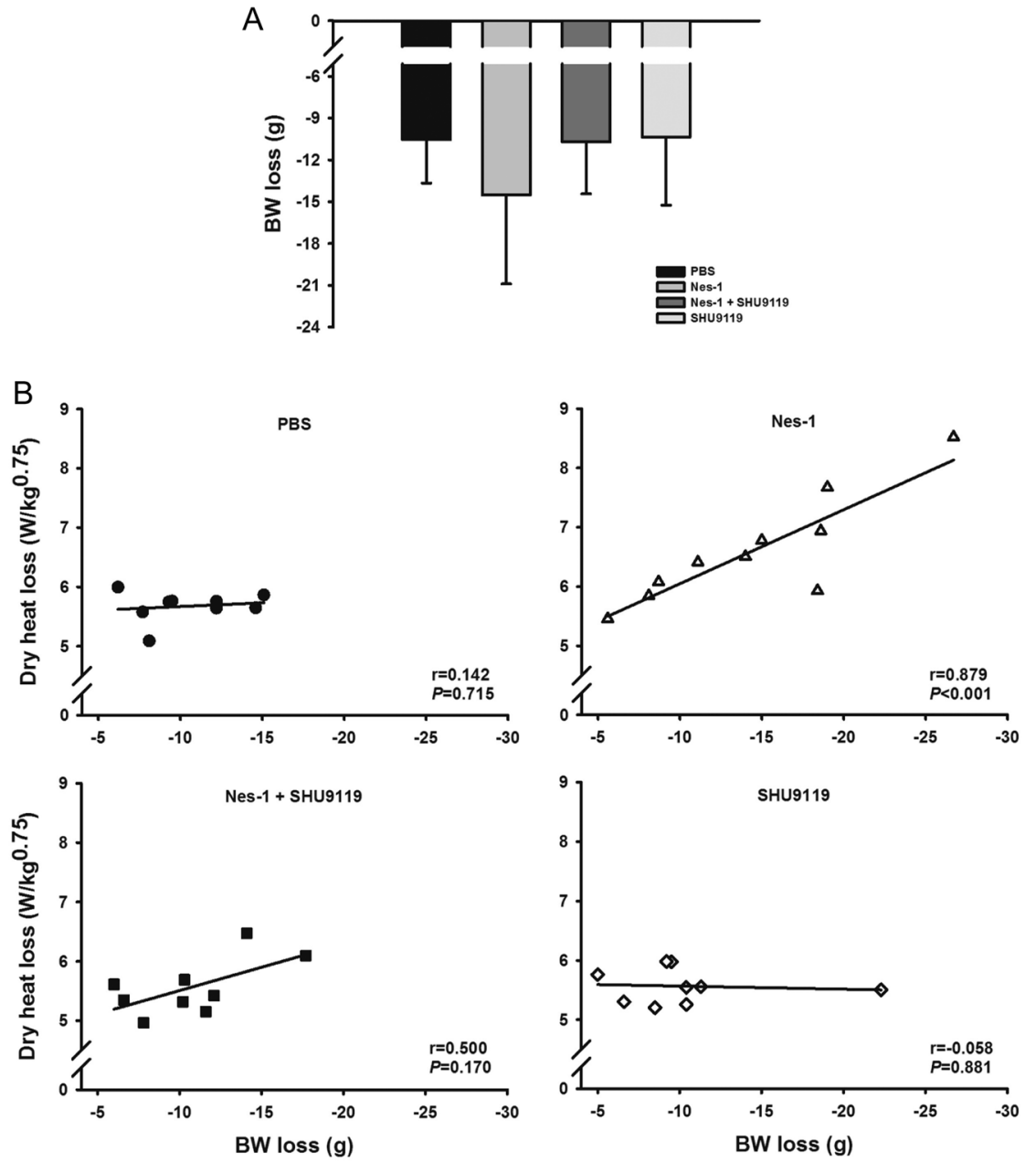

\begin{abstract}
Figure 2
Effect of i.c.v. administration of nesfatin-1 ( $25 \mathrm{pmol} / \mathrm{rat}$ ) and MC3/4R antagonist ( $25 \mathrm{pmol} / \mathrm{rat}$ ) on body weight loss during the 8-h direct calorimetry experiment (A). Correlation analysis (Spearman's coefficient) between body weight loss and average (1-8h) of dry heat loss during the 8-h direct calorimetry experiment (B). Body weights of 24-h fasted rats (9-10/group) were recorded at the beginning and at the end of the calorimetry experiment. Data represent

mean \pm s.D.
\end{abstract}

To test whether nesfatin-1 could also cause elevated tail temperature by direct actions on the vascular system, a wire myography setup was used to test the response to phenylephrine of isolated aorta and tail artery in the presence or absence of nesfatin-1. There was no significant effect on basal or maximal contraction, nor on EC50 (aorta: $2.22 \times 10^{-5}$ vs $1.62 \times 10^{-5} ; t(8)=0.29$, n.s.; tail artery: $5.04 \times 10^{-6}$ vs $9.76 \times 10^{-6} ; t(10)=0.68$, n.s.; PBS $v s$ nesfatin-1, respectively) (Fig. $4 \mathrm{~A}$ and $\mathrm{B}$ ).

\section{Nesfatin-1-induced increase in iBAT temperature correlates with ear and tail temperatures}

The analysis revealed a significant positive correlation between iBAT and ear temperature in both PBS- $(r=0.498$, $P<0.0001)$ and nesfatin-1-treated groups $(r=0.465$, $P<0.001$; Supplementary Fig. 3A). Temperature of the iBAT region was also found to positively correlate with tail temperature in nesfatin-1- $(r=0.514, P<0.0001)$, but not in PBS-treated rats ( $r=0.016$, n.s.; Supplementary Fig. 3B).
Ear temperature also correlated with tail temperature following i.c.v. administration of nesfatin-1 $(r=0.436$, $P<0.001)$, but not after administration of PBS $(r=-0.045$, n.s.; Supplementary Fig. 3C).

\section{Nesfatin-1 increases Pomc and Mc receptor mRNA expression in the hypothalamus}

Immediately before sacrifice and four hours following drug administration, the nesfatin-1-treated group (100 pmol/rat) showed a significantly higher iBAT temperature than the control group $(t(9)=-3.22, P=0.01 ;+2.2 \%)$. In addition, the nesfatin-1-treated group showed a significant increase in iBAT temperature $(t(5)=2.84, P<0.05 ;+2.8 \%)$ with respect to pretreatment iBAT temperature, whereas the PBS-treated group did not $(t(4)=-1.29$, n.s.; $-0.8 \%$ ) (Supplementary Fig. 5A).

I.c.v. administration of nesfatin-1 significantly increased Pomc $(t(9)=-2.37, P<0.05 ;+47 \%)$ and $M c 3 r$ $(t(9)=-2.37, P<0.05$; $+113 \%)$ mRNA expression in the 


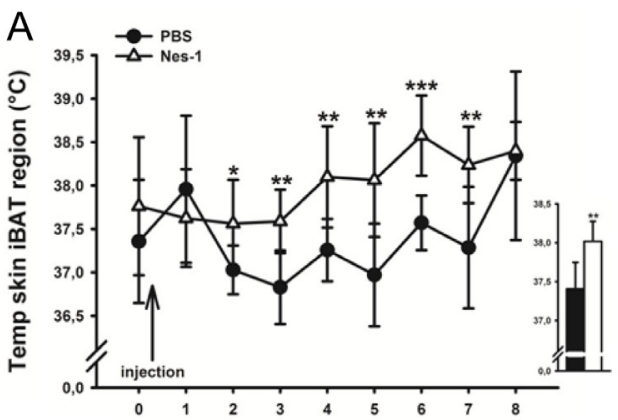

B
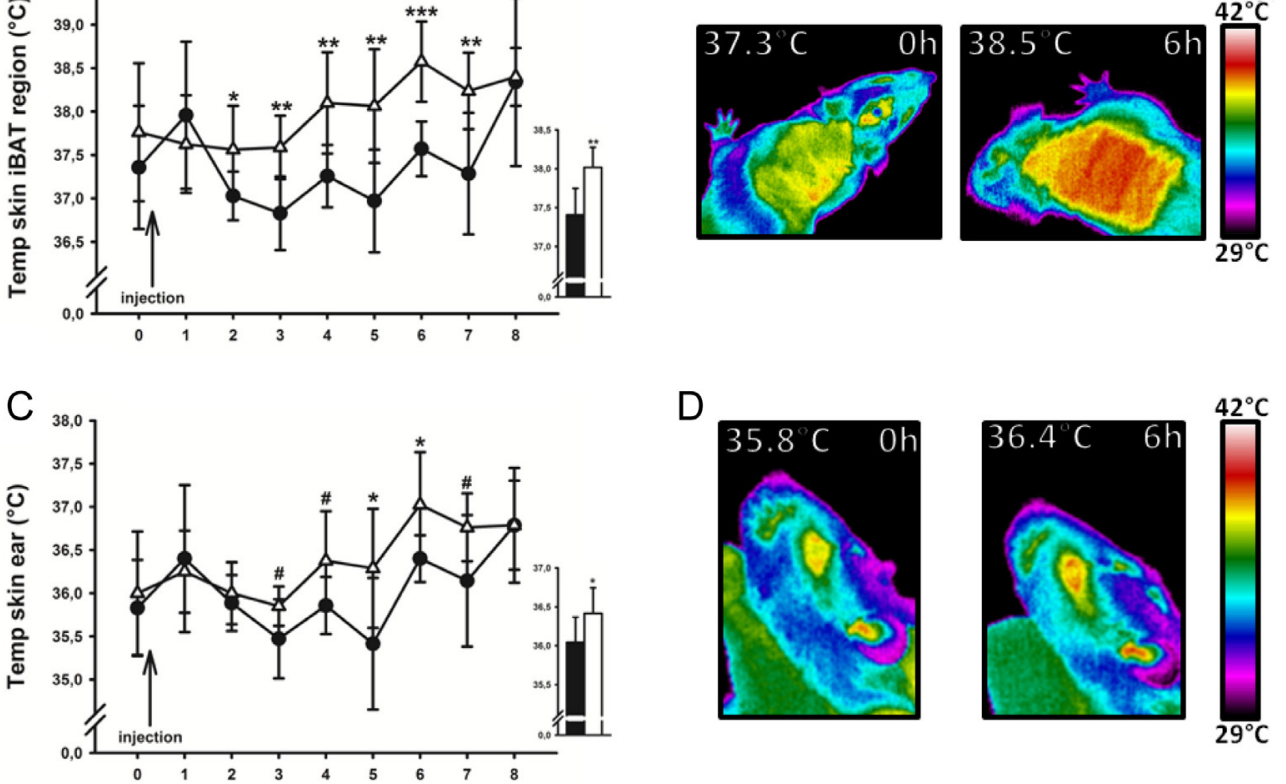

D
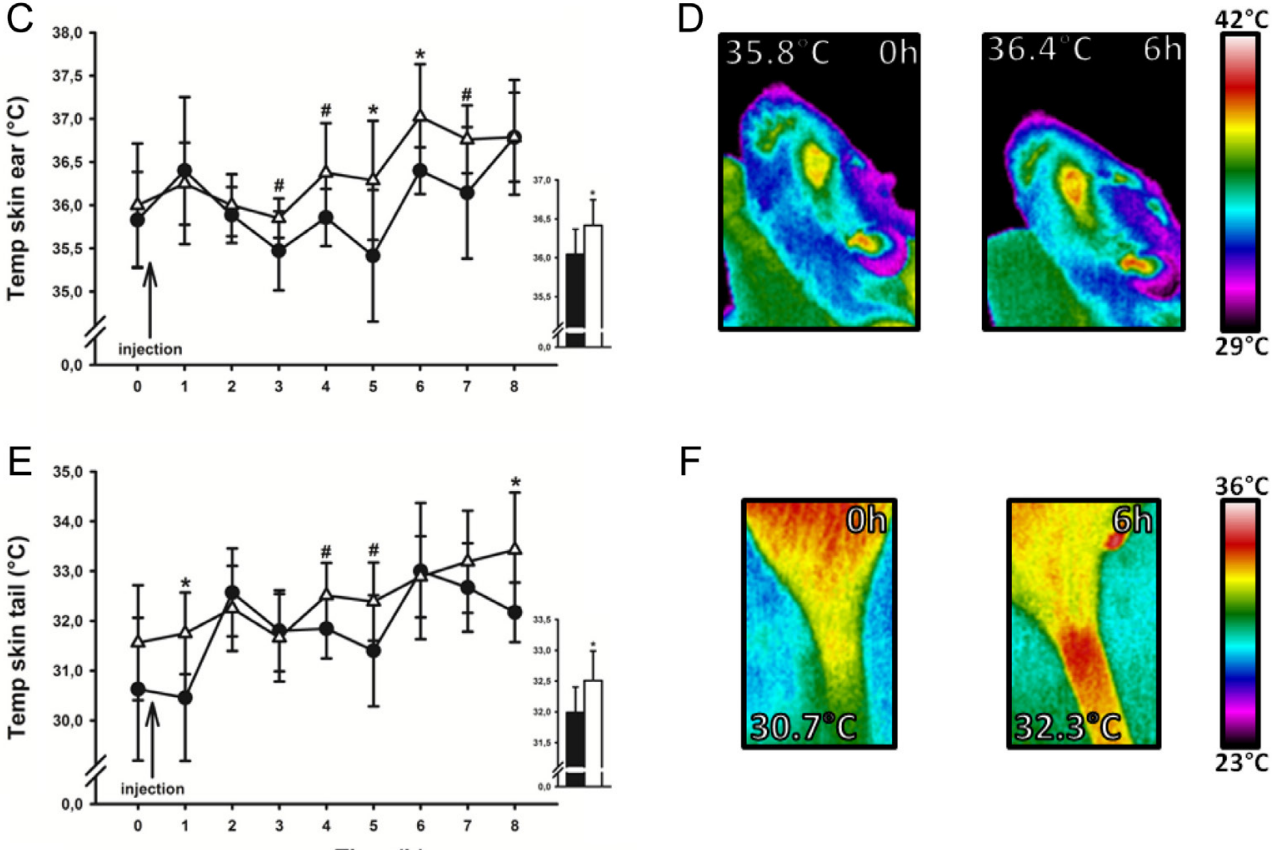

$\mathrm{F}$
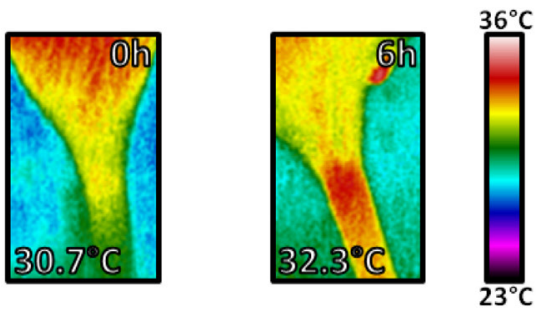

Figure 3

Effects of i.c.v. administration of nesfatin-1 (100 pmol/rat) on iBAT (A), ear (C) and tail (E) temperature measured through thermal imaging. Following drug administration $(5 \mu \mathrm{L} / 2 \mathrm{~min}), 24-\mathrm{h}$ fasted rats (7-8/group) were gently and quickly removed from their home cages, placed under the camera, and pictures of iBAT region, ear and tail were taken every hour. Insets depict average temperature (1-8h). Illustrative pictures of a single experimental animal before and $6 \mathrm{~h}$ following i.c.v. nesfatin-1 administration (B, D and F). Data represent mean \pm s.D. ${ }^{\#} P \leq 0.1$ vs $\mathrm{PBS}$ group; $* P<0.05, * \star P<0.01$, $* * * P<0.001$ vs PBS group (Student's $t$-test).

hypothalamus, as shown in Fig. 5A. A nonsignificant increase in hypothalamic $M c 4 r$ mRNA expression could be also observed $(t(9)=-1.62, P=0.14 ;+53 \%)$. Drug treatment had no effect on the mRNA expression of agouti-related protein $(A g r p)(t(9)=-1.38$, n.s.; $+36 \%)$ (Fig. $5 \mathrm{~A})$.

\section{Nesfatin-1 affects the mRNA expression of thermogenesis-related genes in the iBAT and iWAT}

In theiBAT, i.c.v. administration of nesfatin-1 (100 pmol/rat) significantly increased the mRNA expression of iodothyronine deiodinase 2 (Dio2) $(t(9)=-2.99, P<0.05$; $+370 \%)$ and tended to increase that of $\operatorname{Ucp} 1(t(9)=-1.73$, $P=0.11 ;+74 \%)$ and peroxisome proliferator-activated receptor gamma coactivator-1 alpha (Pgc1a) $(t(9)=-1.76, P=0.11 ;+121 \%)$, as shown in Fig. 5B. Drug treatment had no effect on peroxisomal proliferatoractivated receptor gamma (Pparg $(t(9)=-0.17$, n.s.; $+4 \%$ ), cell death-inducing DNA fragmentation factor (Cidea) $(t(9)=-1.09$, n.s.; $+58 \%)$, beta3-adrenoceptor $(A r 3 b)(t(9)=0.46$, n.s.; $+4 \%)$, adipose triglyceride lipase (Atgl) $(t(9)=0.29$, n.s.; $-4 \%)$ and hormone-sensitive lipase $(H s l)(t(9)=1.31$, n.s.; $-15 \%)$ mRNA expression (Fig. 5B). Interestingly, the analysis revealed a positive correlation between Ucp1 mRNA levels and $\Delta$-iBAT temperature (hour 0-4) that is approaching significance following nesfatin-1 administration $(r=0.771$, $P=0.072)$, but not after PBS administration $(r=-0.600$, n.s.) (Supplementary Fig. 5B). 
A

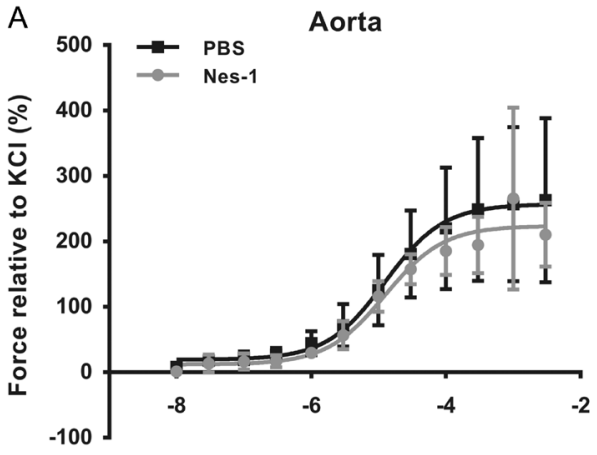

B

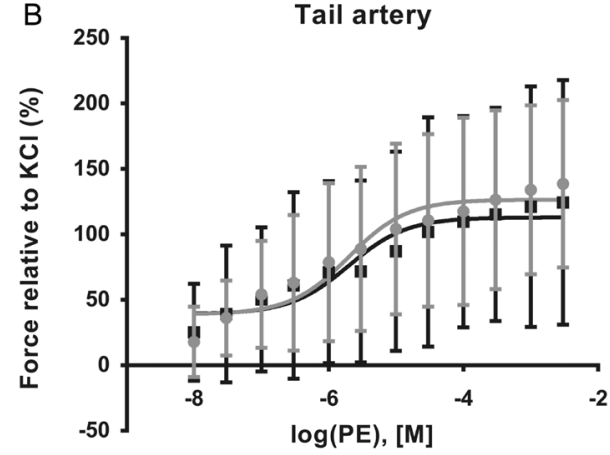

Figure 4

Effects of nesfatin-1 $(10 \mathrm{nM})$ on the vasocontractile response of isolated mouse aorta (A) or tail artery (B) to increasing doses of phenylephrine (PE) compared to controls as assessed by wire myography. The resulting tension forces were normalized to an initial response to high $\mathrm{KCl}$. Data represent mean \pm S.D.

In the iWAT, i.c.v. administration of nesfatin-1 $(100 \mathrm{pmol} / \mathrm{rat})$ also significantly increased the mRNA expression of Dio2 $(t(9)=-2.35, \quad P<0.05 ;+126 \%)$, as shown in Fig. 5D. Drug treatment had no effect on Pparg $(t(9)=-1.36$, n.s.; $+106 \%)$, Pgc1a $(t(9)=-1.02$, n.s.; $+75 \%)$, Cidea $(t(9)=-0.58$, n.s.; $+19 \%), \operatorname{Ar} 3 b(t(9)=1.30$, n.s.; $-36 \%), \operatorname{Atgl}(t(9)=-1.30$, n.s.; $+56 \%)$ and $H s l(t(9)=-1.35$, n.s.; +80\%) mRNA expression. The Ucp1 mRNA levels were undetectable (Fig. 5D).

\section{Nesfatin-1 does not affect UCP1 protein levels in the iBAT}

In the iBAT, i.c.v. administration of nesfatin-1 (100 pmol/rat) did not affect the protein levels of UCP1 $(t(10)=0.41$, n.s.; $-12 \%)$ (Fig. 5C).

\section{Discussion}

The present study clearly shows that the robust increase in dry heat loss induced by i.c.v. nesfatin-1 requires the activation of central MC3/4Rs. These findings are strengthened by thermal imaging data showing that i.c.v. nesfatin-1 increases iBAT and tail temperature.

In direct calorimetry, rats treated with nesfatin-1 showed a significantly higher dry heat loss compared to vehicle-treated animals for up to $8 \mathrm{~h}$, with a maximum effect at 4 and $5 \mathrm{~h}(+24 \%)$, thus confirming our previous observation (Wernecke et al. 2014). Könczöl et al. (2012), with the use of a telemetric system, showed that i.c.v. nesfatin-1 (25 pmol/rat) increases core body temperature. Together with other reports indicating the role of nesfatin-1 in BW homeostasis (Oh-I et al. 2006) and feeding behavior (for review, see Dore et al. 2016), this clearly confirms that the NUCB2/nesfatin-1 system plays an important role in the maintenance of energy balance. Whether the thermogenic action of nesfatin-1 persists for a longer time, and whether it is preserved in genetic and/or diet-induced animal models of obesity, remains to be addressed.

Importantly, we show for the first time that co-administration of the MC3/4R antagonist SHU9119 fully blocks nesfatin-1's thermogenic effect in the direct calorimetry experiment, indicating that nesfatin-1 increases energy expenditure via the activation of central melanocortin receptors. In addition, central administration of nesfatin- 1 elicited an average rise in iBAT $(+1.6 \%)$ and ear temperature $(+1.0 \%)$, indicating increased iBAT thermogenesis and core body temperature, respectively. NUCB2/nesfatin-1 is localized in sympathetic and parasympathetic preganglionic neurons, as well as in the nucleus ambiguus and Edinger-Westphal nucleus (Foo et al. 2008, Goebel et al. 2009, Goebel-Stengel et al. 2011) and appears to be involved in the regulation of a number of autonomic functions. Thus, it is likely that the increases in dry heat loss and iBAT temperature by nesfatin-1 are mediated by an activation of the sympathetic nerves innervating the iBAT. Moreover, in agreement with its distribution, i.c.v. or PVN-specific nesfatin-1 administration was also shown to increase plasma catecholamines (Yilmaz et al. 2015) and sympathetic nerve activity (Tanida et al. 2015), respectively.

The central melanocortin system plays a major role in the regulation of energy homeostasis, not only by affecting feeding behavior but also energy expenditure (Ellacott \& Cone 2006, Jeong et al. 2014). In the regulation of these functions, both MC3R and MC4R were shown to be involved (Butler \& Cone 2003). Pharmacological studies employing the MC3/4R antagonist SHU9119 showed that NUCB2/nesfatin-1 closely interacts with the central melanocortin system to reduce food intake (Oh-I et al. 2006, Yosten \& Samson 2009) and gastrointestinal functions (Li et al. 2013, Wang et al. 2014, Xu et al. 2015,

Published by Bioscientifica Ltd 
A
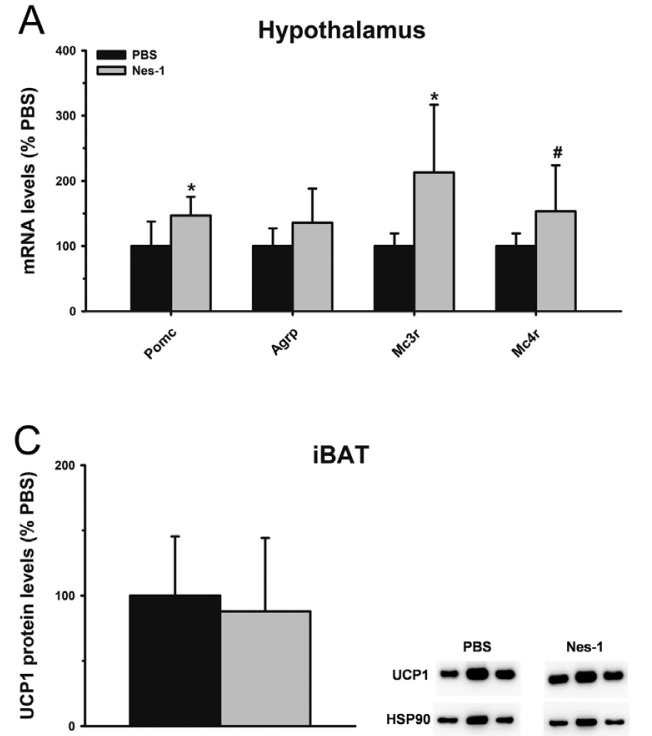

B

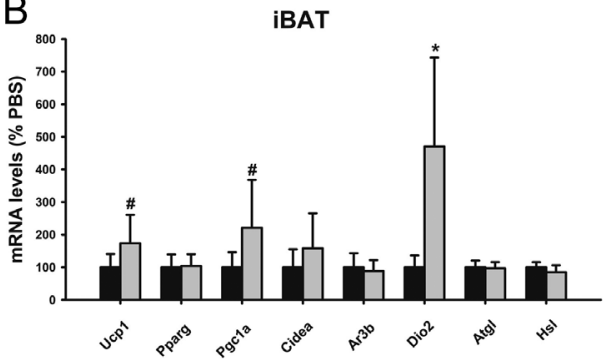

D

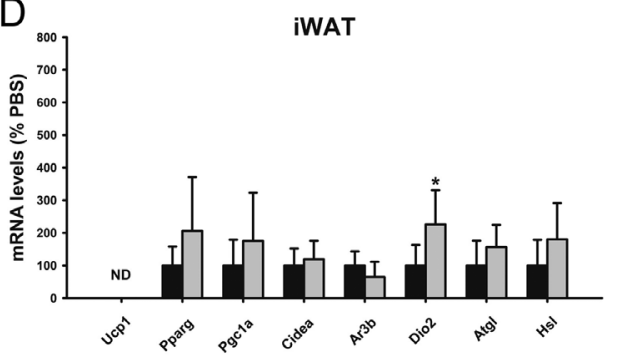

Figure 5

Effects of i.c.v. administration of nesfatin-1 (100 pmol/rat) on mRNA expression in the whole hypothalamus (A), iBAT (B) and iWAT (D) and on UCP1 protein expression in the iBAT (C). 24-h fasted rats (5-6/group) were killed during the light phase $4 \mathrm{~h}$ after drug administration $(5 \mu \mathrm{L} / 2 \mathrm{~min})$, during which iBAT temperature was recorded through thermal imaging. Individual mRNA expression values were normalized to those of Beta-actin and expressed as percent of PBS group. For protein expression, individual values were normalized to those of HSP90 and expressed as percent of PBS group. Data represent mean \pm S.D. ${ }^{P} P \leq 0.1$ vs PBS group; ${ }^{*} P<0.05$ vs PBS group (Student's $t$-test).

Gao et al. 2017), as well as to increase mean arterial pressure (Yosten \& Samson 2009, 2014, Tanida \& Mori 2011, Yilmaz et al. 2015) and sympathetic nerve activity (Tanida \& Mori 2011). Therefore, nesfatin-1 is likely to recruit the central melanocortin system in order to increase sympathetic nerve activity, iBAT thermogenesis and energy expenditure. Taken together, previous and present findings point toward NUCB2/nesfatin-1 as an upstream regulator of the central melanocortin system and thus identify a novel mechanism in the regulation of energy balance.

Several studies suggested the existence of a reciprocal connection between the NUCB2/nesfatin-1 and melanocortin systems. NUCB2/nesfatin-1 and POMC were co-localized in the Arc ( 60-80\%) (Foo et al. 2008); moreover, a functional interaction between these two neuropeptides was previously observed within the hypothalamus, specifically in the Arc (Li et al. 2013) and in the ventromedial nucleus of the hypothalamus (VMH) (Gao et al. 2017). Our findings demonstrate that i.c.v. nesfatin-1 increases the expression of Pomc mRNA as well as Mc3 and Mc4 receptors (albeit the latter non significantly) in the hypothalamus and suggest an interaction between NUCB2/nesfatin-1 and melanocortin systems within this brain area. The hypothalamic melanocortin system plays an important role in regulating autonomic functions and adaptive thermogenesis (Girardet \& Butler 2014).
For instance, i.c.v. SHU9119 administration was shown to abolish the leptin-induced glucose uptake in peripheral tissues, such as skeletal muscles, heart and BAT (Toda et al. 2009). Moreover, VMH or PVN administration of the synthetic MC3/4R agonist melanotan II (MTII) also increases glucose uptake in BAT (Toda et al. 2009), iBAT temperature (Song et al. 2008) and energy expenditure (Gavini et al. 2016). These data, together with our thermogenesis-related and molecular findings, strongly suggest that the interaction between NUCB2/nesfatin-1 and melanocortin system at the level of the hypothalamus accounts for the increase in iBAT temperature and energy expenditure. However, POMC-expressing neurons of the hypothalamus do not only project within this region, but also to other brain regions such as amygdala, nucleus accumbens and NTS (Millington 2007). As SHU9119 was administered i.c.v., the participation of other brain areas expressing MC3/4R in mediating nesfatin-1's thermogenic effect cannot be excluded. The nesfatin-1-induced increase in iBAT thermogenesis (as reflected by increased iBAT temperature) is accompanied by a nonsignificant increase in Pgc1a and Ucp1 mRNA expression, two highly relevant markers of iBAT thermogenesis. However, at this specific time-point ( $4 \mathrm{~h}$ following drug administration), this effect on Ucp1 mRNA expression is not reflected on the protein level, suggesting that nesfatin-1 increases thermogenesis

Published by Bioscientifica Ltd 
by enhancing UCP1 activity rather than synthesis. Nevertheless, UCP1 protein levels could be affected at a different time-point. Of note, a recent study showed that subchronic central nesfatin-1 treatment resulted in increased UCP1 protein levels (Yuan et al. 2017).

I.c.v. nesfatin-1 administration also resulted in a significant increase in the mRNA expression of the cAMP-responsive gene Dio2 in iBAT and iWAT, strongly indicating the activation of the beta-adrenergic receptor/ cAMP signaling pathway. This finding, along with the data on Ucp1 and Pgc1a mRNA expression, is in agreement with the established role of nesfatin-1 in sympathetic nerve activity (Tanida \& Mori 2011, Tanida et al. 2015), and with the increases in dry heat loss and iBAT temperature observed in the present study. In fact, as a trend, the latter is positively correlated with $U_{c p} 1$ mRNA levels. These nesfatin-1-induced effects are likely to be mediated by recruiting the central melanocortin system as ventricle, medial preoptic nucleus or PVN MTII administration was shown to increase both Ucp1 and Pgc1a mRNA levels in the iBAT, along with an increase in temperature, and uptake of 3H-deoxy-glucose and 14C-bromo-palmitate in the iBAT (Song et al. 2008, Toda et al. 2009, Monge-Roffarello et al. 2014a,b). Furthermore, central administration of MTII augments Hsl mRNA expression, indicating increased lipolytic activity (MongeRoffarello et al. 2014a). However, in the present study, i.c.v. nesfatin-1 had no effect on Atgl and Hsl mRNA levels in neither iBAT nor iWAT, suggesting that it does not acutely promote fat utilization. However, the latter can be induced by peripheral nesfatin- 1 administration, as it was inferred from a decrease in the respiratory quotient in indirect calorimetry (Mortazavi et al. 2015). Compatible with these findings, nesfatin-1 treatment promotes Atgl as well as Ucp1 and Pgc1a mRNA expression in brown adipocytes in vitro (Wang et al. 2016), thus implying that nesfatin-1 can also act peripherally to control lipid utilization and iBAT thermogenesis. Interestingly, it was also reported in the same study that nesfatin- 1 is produced by brown adipocytes, suggesting autocrine regulation (Wang et al. 2016). However, to what extent locally produced or circulating nesfatin-1 contributes to iBAT thermogenesis remains to be investigated.

Prolonged sympathetic stimulation of WAT can induce the development of UCP1-positive BAT-like cells, a process often described as 'browning'. In the present study, the mRNA expression of 'browning'-related genes (Ucp1, Pparg, Pgc1a, Ar $3 b$ ) remained unchanged upon nesfatin-1 administration. This outcome is not unexpected, since our animals were acutely treated and sacrificed already $4 \mathrm{~h}$ following administration (Nedergaard \& Cannon 2014). Whether nesfatin-1 plays a role in 'browning' remains to be investigated in chronic application studies.

Noteworthy, not only heat production was induced, but we also observed an increase in tail surface temperature after administering i.c.v. nesfatin-1, indicating increased tail vessel vasodilation and heat dissipation. This effect likely constitutes a counter-regulatory mechanism in response to the rise in heat production (Warner \& Mittag 2014). This hypothesis is supported by the positive correlation between both iBAT and ear temperature with tail temperature in animals treated with nesfatin-1 but not PBS. This finding is of particular interest and underpins the magnitude of the increase in thermogenesis, which is creating a demand to dissipate heat through tail vessel vasodilation, even though on the level of the whole organism, i.c.v. nesfatin-1 rather enhances sympathetic nerve activity (Tanida \& Mori 2011, Tanida et al. 2015) and release of catecholamines (Yilmaz et al. 2015). Our observation, that both ear and rectal temperature (reflecting core body temperature) are increased upon nesfatin-1 treatment, suggests that heat dissipation over the tail surface is not sufficient to keep core body temperature constant in the condition of increased iBAT activity. This finding is also supported by Könczöl et al. (2012), who has reported an increase in core body temperature after central nervous nesfatin-1 administration using a biotelemetry system (Minimitters). While a spill-over of nesfatin-1 from the cerebral spinal fluid into the blood cannot be ruled out, a local action of nesfatin-1 to relax vascular smooth muscle is highly unlikely since nesfatin-1, on the level of the blood vessel, rather precludes vasodilation. In fact, in vitro nesfatin-1 application prevented the sodium nitroprusside-induced relaxation of smooth muscle in mesenteric artery, whereas it did not affect noradrenaline and 5-hydroxytryptamineinduced contractions (Yamawaki et al. 2012). These observations are confirmed by results of the present study, as the same concentration of nesfatin- $1(10 \mathrm{nM})$ had no effect per se and on phenylephrine-induced contraction in both aorta and tail artery.

In summary, we provide evidence that i.c.v. nesfatin-1 activates the central melanocortin system to increase dry heat loss. The increase in both iBAT and tail temperature are appear to importantly contribute to this effect. We propose that the activation of the sympathetic nervous system is the underlying mechanism connecting central NUCB2/nesfatin-1 and the melanocortin system with iBAT thermogenesis.

Overall, our findings provide novel insights into the role of NUCB2/nesfatin-1 as an upstream regulator of the melanocortin system in the control of energy homeostasis

Published by Bioscientifica Ltd 
and may represent a promising target for the treatment of obesity and metabolic disorders. To this end, studies in animal models of diet-induced obesity are needed.

\section{Supplementary data}

This is linked to the online version of the paper at http://dx.doi.org/10.1530/ JOE-17-0151.

\section{Declaration of interest}

The authors declare that there is no conflict of interest that could be perceived as prejudicing the impartiality of the research reported.

\section{Funding}

This work was made possible by grants of the Deutsche Forschungsgemeinschaft to H L and C S (GRK 1957 and TR-SFB134) and of the DDS - Deutsche Diabetes Stiftung $(333 / 02 / 13)$ to C S.

\section{Acknowledgements}

The authors thank Christine Eichholz and Angela Oldörp for excellent technical assistance, and Regina Krotenko for her help in scoring images.

\section{References}

Bamshad M, Song CK \& Bartness TJ 1999 CNS origins of the sympathetic nervous system outflow to brown adipose tissue. American Journal of Physiology 276 R1569-R1578.

Brailoiu GC, Dun SL, Brailoiu E, Inan S, Yang J, Chang JK \& Dun NJ 2007 Nesfatin-1: distribution and interaction with a $\mathrm{G}$ protein-coupled receptor in the rat brain. Endocrinology 148 5088-5094. (doi:10.1210/en.2007-0701)

Butler AA \& Cone RD 2003 Knockout studies defining different roles for melanocortin receptors in energy homeostasis. Annals of the New York Academy of Sciences 994 240-245. (doi:10.1111/j.1749-6632.2003. tb03186.x)

Dore R, Iemolo A, Smith KL, Wang X, Cottone P \& Sabino V 2013 CRF mediates the anxiogenic and anti-rewarding, but not the anorectic effects of PACAP. Neuropsychopharmacology 38 2160-2169. (doi:10.1038/npp.2013.113)

Dore R, Levata L, Lehnert H \& Schulz C 2016 Nesfatin-1: functions and physiology of a novel regulatory peptide. Journal of Endocrinology 232 R45-R65. (doi:10.1530/JOE-16-0361)

Ellacott KL \& Cone RD 2006 The role of the central melanocortin system in the regulation of food intake and energy homeostasis: lessons from mouse models. Philosophical Transactions of the Royal Society of London Series B 361 1265-1274. (doi:10.1098/rstb.2006.1861)

Fan W, Boston BA, Kesterson RA, Hruby VJ \& Cone RD 1997 Role of melanocortinergic neurons in feeding and the agouti obesity syndrome. Nature 385 165-168. (doi:10.1038/385165a0)

Fan W, Morrison SF, Cao WH \& Yu P 2007 Thermogenesis activated by central melanocortin signaling is dependent on neurons in the rostral raphe pallidus (rRPa) area. Brain Research 1179 61-69. (doi:10.1016/j. brainres.2007.04.006)

Feng H, Wang Q, Guo F, Han X, Pang M, Sun X, Gong Y \& Xu L 2017 Nesfatin-1 influences the excitability of gastric distension-responsive neurons in the ventromedial hypothalamic nucleus of rats. Physiological Research 66 335-344.

Foo KS, Brismar H \& Broberger C 2008 Distribution and neuropeptide coexistence of nucleobindin-2 mRNA/nesfatin-like immunoreactivity in the rat CNS. Neuroscience 156 563-579. (doi:10.1016/j.neuroscience.2008.07.054)
Gao S, Guo F, Sun X, Zhang N, Gong Y \& Xu L 2017 The inhibitory effects of nesfatin-1 in ventromedial hypothalamus on gastric function and its regulation by nucleus accumbens. Frontiers in Physiology 7 634. (doi:10.3389/fphys.2016.00634)

García-Galiano D, Navarro VM, Roa J, Ruiz-Pino F, Sánchez-Garrido MA, Pineda R, Castellano JM, Romero M, Aguilar E, Gaytán F, et al. 2010 The anorexigenic neuropeptide, nesfatin-1, is indispensable for normal puberty onset in the female rat. Journal of Neuroscience $\mathbf{3 0}$ 7783-7792. (doi:10.1523/JNEUROSCI.5828-09.2010)

Gavini CK, Jones WC 2nd \& Novak CM 2016 Ventromedial hypothalamic melanocortin receptor activation: regulation of activity energy expenditure and skeletal muscle thermogenesis. Journal of Physiology 594 5285-5301. (doi:10.1113/JP272352)

Girardet C \& Butler AA 2014 Neural melanocortin receptors in obesity and related metabolic disorders. Biochimica et Biophysica Acta 1842 482-494. (doi:10.1016/j.bbadis.2013.05.004)

Goebel M, Stengel A, Wang L, Lambrecht NW \& Taché Y 2009 Nesfatin-1 immunoreactivity in rat brain and spinal cord autonomic nuclei. Neuroscience Letters 452 241-246. (doi:10.1016/j.neulet.2009.01.064)

Goebel-Stengel M, Wang L, Stengel A \& Taché Y 2011 Localization of nesfatin-1 neurons in the mouse brain and functional implication. Brain Research 1396 20-34. (doi:10.1016/j.brainres.2011.04.031)

Hoefig CS, Harder L, Oelkrug R, Meusel M, Vennström B, Brabant G \& Mittag J 2016 Thermoregulatory and cardiovascular consequences of a transient thyrotoxicosis and recovery in male mice. Endocrinology 157 2957-2967. (doi:10.1210/en.2016-1095)

Hwa JJ, Ghibaudi L, Gao J \& Parker EM 2001 Central melanocortin system modulates energy intake and expenditure of obese and lean Zucker rats. American Journal of Physiology: Regulatory, Integrative and Comparative Physiology 281 R444-R451.

Inhoff T, Stengel A, Peter L, Goebel M, Taché Y, Bannert N, Wiedenmann B, Klapp BF, Mönnikes H \& Kobelt P 2010 Novel insight in distribution of nesfatin-1 and phospho-mTOR in the arcuate nucleus of the hypothalamus of rats. Peptides 31 257-262. (doi:10.1016/j.peptides.2009.11.024)

Jastroch M, Hirschberg V \& Klingenspor M 2012 Functional characterization of UCP1 in mammalian HEK293 cells excludes mitochondrial uncoupling artefacts and reveals no contribution to basal proton leak. Biochimica et Biophysica Acta 1817 1660-1670. (doi:10.1016/j.bbabio.2012.05.014)

Jeong JK, Kim JG \& Lee BJ 2014 Participation of the central melanocortin system in metabolic regulation and energy homeostasis. Cellular and Molecular Life Sciences 71 3799-3809. (doi:10.1007/s00018-014-1650-z)

Jöhren O, Golsch C, Dendorfer A, Qadri F, Häuser W \& Dominiak P 2003 Differential expression of AT1 receptors in the pituitary and adrenal gland of SHR and WKY. Hypertension 41 984-990. (doi:10.1161/01. HYP.0000062466.38314.B7)

Kohno D, Nakata M, Maejima Y, Shimizu H, Sedbazar U, Yoshida N, Dezaki K, Onaka T, Mori M \& Yada T 2008 Nesfatin-1 neurons in paraventricular and supraoptic nuclei of the rat hypothalamus coexpress oxytocin and vasopressin and are activated by refeeding. Endocrinology 149 1295-1301. (doi:10.1210/en.2007-1276)

Könczöl K, Pinter O, Ferenczi S, Varga J, Kovács K, Palkovits M, Zelena D \& Tóth ZE 2012 Nesfatin-1 exerts long-term effect on food intake and body temperature. International Journal of Obesity 36 1514-1521. (doi:10.1038/ijo.2012.2)

Li ZL, Xu L, Sun XR, Guo FF, Gong YL \& Gao SL 2013 Central nesfatin-1 influences the excitability of ghrelin-responsive gastric distension neurons in the arcuate nucleus and reduces gastric motility in rats. European Journal of Neuroscience 38 3636-3643. (doi:10.1111/ejn.12366)

Maejima Y, Sedbazar U, Suyama S, Kohno D, Onaka T, Takano E, Yoshida N, Koike M, Uchiyama Y, Fujiwara K, et al. 2009 Nesfatin1-regulated oxytocinergic signaling in the paraventricular nucleus causes anorexia through a leptin-independent melanocortin pathway. Cell Metabolism 10 355-365. (doi:10.1016/j.cmet.2009.09.002)

Millington GW 2007 The role of proopiomelanocortin (POMC) neurones in feeding behaviour. Nutrition and Metabolism 418. (doi:10.1186/1743-7075-4-18) 
Monge-Roffarello B, Labbe SM, Lenglos C, Caron A, Lanfray D, Samson P \& Richard D 2014a The medial preoptic nucleus as a site of the thermogenic and metabolic actions of melanotan II in male rats. American Journal of Physiology: Regulatory, Integrative and Comparative Physiology 307 R158-R166. (doi:10.1152/ajpregu.00059.2014)

Monge-Roffarello B, Labbe SM, Roy MC, Lemay ML, Coneggo E, Samson P, Lanfray D \& Richard D 2014b The PVH as a site of CB1mediated stimulation of thermogenesis by MC4R agonism in male rats. Endocrinology 155 3448-3458. (doi:10.1210/en.2013-2092)

Mortazavi S, Gonzalez R, Ceddia R \& Unniappan S 2015 Long-term infusion of nesfatin-1 causes a sustained regulation of whole-body energy homeostasis of male Fischer 344 rats. Frontiers in Cell and Developmental Biology 3 22. (doi:10.3389/fcell.2015.00022)

Nakata M, Gantulga D, Santoso P, Zhang B, Masuda C, Mori M, Okada T \& Yada T 2016 Paraventricular NUCB2/Nesfatin-1 supports oxytocin and vasopressin neurons to control feeding behavior and fluid balance in male mice. Endocrinology 157 2322-2332. (doi:10.1210/en.2015-2082)

Nedergaard J \& Cannon B 2014 The browning of white adipose tissue: some burning issues. Cell Metabolism 20 396-407. (doi:10.1016/j. cmet.2014.07.005)

Oh-I S, Shimizu H, Satoh T, Okada S, Adachi S, Inoue K, Eguchi H, Yamamoto M, Imaki T, Hashimoto K, et al. 2006 Identification of nesfatin-1 as a satiety molecule in the hypothalamus. Nature $\mathbf{4 4 3}$ 709-712. (doi:10.1038/nature05162)

Oldfield BJ, Giles ME, Watson A, Anderson C, Colvill LM \& McKinley MJ 2002 The neurochemical characterisation of hypothalamic pathways projecting polysynaptically to brown adipose tissue in the rat. Neuroscience 110 515-526. (doi:10.1016/S0306-4522(01)00555-3)

Paxinos G \& Watson C 2007 The rat brain in stereotaxic coordinates, 6th Edition, p. 456. London, Oxford: Academic Press.

Price CJ, Samson WK \& Ferguson AV 2008 Nesfatin-1 inhibits NPY neurons in the arcuate nucleus. Brain Research 1230 99-106. (doi:10.1016/j.brainres.2008.06.084)

Ramanjaneya M, Chen J, Brown JE, Tripathi G, Hallschmid M, Patel S, Kern W, Hillhouse EW, Lehnert H, Tan BK et al. 2010 Identification of nesfatin-1 in human and murine adipose tissue: a novel depotspecific adipokine with increased levels in obesity. Endocrinology 151 3169-3180. (doi:10.1210/en.2009-1358)

Schulz C, Paulus K, Jöhren O \& Lehnert H 2012 Intranasal leptin reduces appetite and induces weight loss in rats with diet-induced obesity (DIO). Endocrinology 153 143-153. (doi:10.1210/en.2011-1586)

Sedbazar U, Ayush EA, Maejima Y \& Yada T 2014 Neuropeptide Y and alpha-melanocyte-stimulating hormone reciprocally regulate nesfatin-1 neurons in the paraventricular nucleus of the hypothalamus. Neuroreport 25 1453-1458. (doi:10.1097/WNR.0000000000000293)

Song CK, Vaughan CH, Keen-Rhinehart E, Harris RB, Richard D \& Bartness TJ 2008 Melanocortin-4 receptor mRNA expressed in sympathetic outflow neurons to brown adipose tissue: neuroanatomical and functional evidence. American Journal of Physiology: Regulatory, Integrative and Comparative Physiology 295 R417-R428. (doi:10.1152/ajpregu.00174.2008)

Stengel A, Goebel M, Wang L, Rivier J, Kobelt P, Mönnikes H, Lambrecht NW \& Taché Y 2009a Central nesfatin-1 reduces dark-phase food intake and gastric emptying in rats: differential role of corticotropin-releasing factor2 receptor. Endocrinology 150 4911-4919. (doi:10.1210/en.2009-0578)

Stengel A, Goebel M, Yakubov I, Wang L, Witcher D, Coskun T, Taché Y, Sachs G \& Lambrecht NW 2009b Identification and characterization of nesfatin-1 immunoreactivity in endocrine cell types of the rat gastric oxyntic mucosa. Endocrinology 150 232-238. (doi:10.1210/en.2008-0747)

Tanida M \& Mori M 2011 Nesfatin-1 stimulates renal sympathetic nerve activity in rats. Neuroreport 22 309-312. (doi:10.1097/WNR.0b013e328346107f)

Tanida M, Gotoh H, Yamamoto N, Wang M, Kuda Y, Kurata Y, Mori M \& Shibamoto T 2015 Hypothalamic nesfatin-1 stimulates sympathetic nerve activity via hypothalamic ERK signaling. Diabetes 64 3725-3736. (doi:10.2337/db15-0282)
Toda C, Shiuchi T, Lee S, Yamato-Esaki M, Fujino Y, Suzuki A, Okamoto S \& Minokoshi Y 2009 Distinct effects of leptin and a melanocortin receptor agonist injected into medial hypothalamic nuclei on glucose uptake in peripheral tissues. Diabetes 58 2757-2765. (doi:10.2337/db09-0638)

Vogel B, Wagner H, Gmoser J, Worner A, Loschberger A, Peters L, Frey A, Hofmann U \& Frantz S 2016 Touch-free measurement of body temperature using close-up thermography of the ocular surface. MethodsX 3 407-416. (doi:10.1016/j.mex.2016.05.002)

Wang Q, Guo F, Sun X, Gao S, Li Z, Gong Y \& Xu L 2014 Effects of exogenous nesfatin-1 on gastric distention-sensitive neurons in the central nucleus of the amygdala and gastric motility in rats. Neuroscience Letters 582 65-70. (doi:10.1016/j.neulet.2014.09.003)

Wang Y, Li Z, Zhang X, Xiang X, Li Y, Mulholland MW \& Zhang W 2016 Nesfatin-1 promotes brown adipocyte phenotype. Scientific Reports 6 article 34747. (doi:10.1038/srep34747)

Warner A \& Mittag J 2014 Brown fat and vascular heat dissipation: the new cautionary tail. Adipocyte 3 221-223. (doi:10.4161/adip.28815)

Warner A, Rahman A, Solsjö P, Gottschling K, Davis B, Vennstrom B, Arner A \& Mittag J 2013 Inappropriate heat dissipation ignites brown fat thermogenesis in mice with a mutant thyroid hormone receptor alpha1. PNAS 110 16241-16246. (doi:10.1073/pnas.1310300110)

Wernecke K, Lamprecht I, Jöhren O, Lehnert H \& Schulz C 2014 Nesfatin-1 increases energy expenditure and reduces food intake in rats. Obesity 22 1662-1668. (doi:10.1002/oby.20736)

Williams DL, Bowers RR, Bartness TJ, Kaplan JM \& Grill HJ 2003 Brainstem melanocortin 3/4 receptor stimulation increases uncoupling protein gene expression in brown fat. Endocrinology 144 4692-4697. (doi:10.1210/en.2003-0440)

Xu L, Wang Q, Guo F, Pang M, Sun X, Gao S \& Gong Y 2015 Nesfatin-1 signaling in the basom edial amygdala modulates the gastric distensionsensitive neurons discharge and decreases gastric motility via melanocortin 3/4 receptors and modified by the arcuate nucleus. European Journal of Pharmacology 764 164-172. (doi:10.1016/j.ejphar.2015.07.002)

Yamawaki H, Takahashi M, Mukohda M, Morita T, Okada M \& Hara Y 2012 A novel adipocytokine, nesfatin-1 modulates peripheral arterial contractility and blood pressure in rats. Biochemical and Biophysical Research Communications 418 676-681. (doi:10.1016/j. bbrc.2012.01.076)

Yilmaz MS, Altinbas B, Guvenc G, Erkan LG, Avsar O, Savci V, Kucuksen DU, Arican I \& Yalcin M 2015 The role of centrally injected nesfatin-1 on cardiovascular regulation in normotensive and hypotensive rats. Autonomic Neuroscience 193 63-68. (doi:10.1016/j. autneu.2015.07.009)

Yosten GL \& Samson WK 2009 Nesfatin-1 exerts cardiovascular actions in brain: possible interaction with the central melanocortin system. American Journal of Physiology: Regulatory, Integrative and Comparative Physiology 297 R330-R336. (doi:10.1152/ajpregu.90867.2008)

Yosten GL \& Samson WK 2010 The anorexigenic and hypertensive effects of nesfatin- 1 are reversed by pretreatment with an oxytocin receptor antagonist. American Journal of Physiology: Regulatory, Integrative and Comparative Physiology 298 R1642-R1647. (doi:10.1152/ajpregu.00804.2009)

Yosten GL \& Samson WK 2014 Neural circuitry underlying the central hypertensive action of nesfatin-1: melanocortins, corticotropinreleasing hormone, and oxytocin. American Journal of Physiology: Regulatory, Integrative and Comparative Physiology 306 R722-R727. (doi:10.1152/ajpregu.00396.2013)

Yuan JH, Chen X, Dong J, Zhang D, Song K, Zhang Y, Wu GB, Hu XH, Jiang ZY \& Chen P 2017 Nesfatin-1 in the lateral parabrachial nucleus inhibits food intake, modulates excitability of glucosensing neurons, and enhances UCP1 expression in brown adipose tissue. Frontiers in Physiology 8 235. (doi:10.3389/fphys.2017.00235)

Zhang W \& Bi S 2015 Hypothalamic regulation of brown adipose tissue thermogenesis and energy homeostasis. Frontiers in Endocrinology 6136. (doi:10.3389/fendo.2015.00136)

Received in final form 11 August 2017

Accepted 15 August 2017

Published by Bioscientifica Ltd. 